\title{
АНАЛИЗ ВИДОВ И МЕТОДОВ УПРАВЛЕНИЯ БЕСПИЛОТНЫХ ЛЕТАТЕЛЬНЫХ АППАРАТОВ
}

\section{ANALYSIS OF TYPES AND METHODS OF CONTROL OF UNMANNED AERIAL VEHICLES}

\section{Yu. Litvinov \\ T. Keribayeva}

Summary. In the modern world, unmanned aircraft systems (UAS) are increasingly being used in many sectors of the national economy. A large number of BAS systems for various purposes with a wide range of weight and size characteristics have been created. The article gives a classification of unmanned aerial vehicles (UAVs). The article also discusses the criteria for safe flight of UAVs. An algorithm for adjusting the flight task depending on the specific situation and the type of UAV is developed.

The identification of the situation during the UAV flight is considered. The classification of flight situations is made, which includes five classes according to the degree of danger. The classification is based on the amount of deviation from the specified parameters of the flight task. The proposed approach takes into account different types of unmanned aerial vehicles, which makes it universal for each flight task. As a result, the identification of the current flight situation increases the pilot's awareness of the situation and provides the necessary level of flight safety.

Keywords: monitoring, unmanned aerial vehicles, flight task, navigation, classification of UAV types.

\author{
Литвинов Юрий Георгиевич \\ К.ф.- м.н., ассочирированный профессор, \\ AO «Академия Гражданской Авиации», (2. Алматы, \\ Республика Казахстан) \\ yurii-litvinov@mail.ru \\ Керибаева Талшын Бакытжанкызы \\ Докторант, АО «Академия Гражданской Авиачии», \\ (2. Алматы, Республика Казахстан) \\ talshyn.keribayeva@gmail.com
}

Аннотация. В современном мире беспилотные авиационные системы (БАС) находят всё более широкое применение во многих отраслях народного хозяйства. Создано большое количество БАС самого различного назначения с широким диапазоном массогабаритных характеристик. В статье дана классификация беспилотных летательных аппаратов (БПЛА). В статье так же рассматриваются критерии безопасного полета БПЛА. Разработан алгоритм корректировки полетного задания в зависимости от конкретной ситуации и типа БПЛА.

Рассмотрена идентификация ситуации при полете БПЛА. Произведена классификация ситуаций полета, которая включает пять классов по степени опасности. Классификация основана на величине отклонения от заданных параметров полетного задания. Предлагаемый подход учитывает различные типы беспилотных летательных аппаратов, что делает его универсальный для каждого полетного задания. В результате идентификация текущей полетной ситуации повышается осведомленность пилота о ситуации и обеспечивается необходимый уровень безопасности полетов.

Ключевые слова: мониторинг, беспилотные летательные аппараты, полетное задание, навигация, классификация типов БПЛА.

нении задач ведения наблюдения. Они позволяют оператору наблюдать и отслеживать обстановку в любом заданном месте [11, с. 86].

\section{ВиАы беспилотных ^етате^ьных аппаратов}

БПЛА невозможно классифицировать по тем или иным характеристикам, так как их огромное множество. Разнообразию дронов не видно конца, так как производители пока не ограничены никакими стандартами. В результате сегодня отсутствуют требования со стороны авиационных регуляторов о том, как БПЛА должен быть оснащен [5, с. 4].

Беспилотники могут быть как самолетного, так и вертолетного типов [8, с. 77]. Они отличаются габари- 
Таблица 1. Классификация БПЛА

\begin{tabular}{|c|c|c|c|c|}
\hline $\begin{array}{l}\mathbf{N} \\
\text { класса }\end{array}$ & Класс БПЛА & Взлетная масса, кг & $\begin{array}{l}\text { Дальность } \\
\text { действия, км }\end{array}$ & Примеры БПЛА \\
\hline 1 & $\begin{array}{l}\text { Микро и мини -ближнего радиуса } \\
\text { действия }\end{array}$ & 5 & $25-40$ & $\begin{array}{l}\text { Geoscan 101, ZALA 421-11, } \\
\text { Элерон, БРАT }\end{array}$ \\
\hline 2 & Легкие малого радиуса действия & $5-50$ & $10-120$ & Geoscan 300, Орлан -10 \\
\hline 3 & Легкие среднего радиуса действия & $50-100$ & $70-150$ & $\begin{array}{l}\text { ZALA 421-09, Дозор - 2, } \\
\text { Пчела - 1Т }\end{array}$ \\
\hline 4 & Средние & $100-300$ & $150-1000$ & $\begin{array}{l}\text { Бином, Комар, Берта, } \\
\text { Беркут, Иркут - } 200\end{array}$ \\
\hline 5 & Среднетяжелые & $300-500$ & $70-300$ & $\begin{array}{l}\text { Колибри, Данэм, Аист, } \\
\text { Дозор - } 3\end{array}$ \\
\hline 6 & Тяжелые среднего радиуса действия & $>500$ & $70-300$ & $\begin{array}{l}\text { Tу - 243, Иркут - 850, } \\
\text { Нарт }\end{array}$ \\
\hline 7 & $\begin{array}{l}\text { Тяжелые большой } \\
\text { продолжительности полета }\end{array}$ & $>1500$ & 1500 & $\begin{array}{l}\text { Predator, Heron, Зонд - 1, } \\
\text { БасC }\end{array}$ \\
\hline
\end{tabular}

тами, функциональностью, дальностью полетов, уровнем автономности и другими характеристиками.

За последнее время накоплен большой опыт в создании беспилотных летательных аппаратов [12, с. 119]. Существуют беспилотные аппараты различной конструкции с различным весом, дальностью полета, массой полезной нагрузки, вариантов посадки и запуска. Повышенный интерес к их использованию вызван простотой их конструкции, относительно небольшой стоимостью, оперативностью. Классификация БПЛА по размеру приведена в Таблица 1.

Конструкция и функциональность меняются в зависимости от назначения аппарата [9, с. 38]. Есть модели дронов, которые умеют принимать команды человека и реагировать на них. В таких устройствах установлены специальные модули-приемники команд.

Для мониторинга обычно используются БПЛА 1 и 2 класса. Это обусловлено тем, что при увеличении массы увеличивается энергия, выделяемая при его посадке, что может повредить БПЛА. БПЛА, сконструированные по типу вертолета лишены этого недостатка, но они не могут летать на далекие расстояния.

\section{Фотоаппаратура, устанавливаемая на БП^А}

Существует огромный диапазон устройств записи изображений, доступных для применения на БПЛА. Типичные датчики можно условно классифицировать следующим образом:

- экшн и рыбий глаз камеры;

- камеры для потребительского рынка;

- камеры для профессионального применения;

- промышленные камеры;
- метрические камеры для явных фотограмметрических применений;

- скоростные камеры;

- панорамные камеры;

- многокамерные системы.

Доступность цифровых устройств регистрирования варьируется от массовых продуктов, например, камер смартфонов, до специальных высокопроизводительных датчиков, используемых для специальных применений, таких как высокоскоростная визуализация. Датчики с глобальным затвором требуются для большинства динамических применений, когда камера или объект движутся относительно друг друга.

Фотоаппаратура, устанавливаемая на БПЛА, позволяет получить цифровое изображение местности с разрешение 3 см на пиксель. Обработка изображений производится так же как и в традиционной аэрофотосъемке. Применение двухчастотной ГЛОНАС / GPS системы глобального позиционирования для определения центров фотографирования дает точность их определения не хуже 5 см.

\section{Управление безопасностью полета беспилотного летательного аппарата}

Правильная работа беспилотного летательного аппарата (БПЛА) во время миссии учитывает влияние ряда факторы, вызывающих отклонения некоторых параметров движения от их оптимальных значений [6, с 79], [7, с 301]. Эксплуатация БПЛА несомненно, предполагает обеспечение определенного уровня безопасности полетов. Безопасность летного задания зависит от целого ряда факторов, отражающих потенциальные опасности. 
Таблица 2. Ограничения безопасности полета в соответствии с классом ситуации и типом БПЛА

\begin{tabular}{|l|l|l|l|l|} 
Тип БПЛА & $\begin{array}{l}\text { Сложные условия } \\
\text { полета }\end{array}$ & $\begin{array}{l}\text { Опасные условия } \\
\text { полета }\end{array}$ & $\begin{array}{l}\text { Чрезвычайные } \\
\text { условия полета }\end{array}$ & Катастрофические ситуации \\
\hline 1 & $10^{-3}$ & $10^{-4}$ & $10^{-5}$ & $10^{-6}$ \\
\hline 2 & $10^{-3}$ & $10^{-5}$ & $10^{-6}$ & $10^{-7}$ \\
\hline 3 & $10^{-3}$ & $10^{-5}$ & $10^{-7}$ & $10^{-8}$ \\
\hline 4 & $10^{-3}$ & $10^{-5}$ & $10^{-7}$ & $10^{-9}$ \\
\hline
\end{tabular}

Реально на полет БПЛА влияет воздушное пространство, работа технических систем. Все это, создает предпосылки для целого комплекса факторов, негативно влияющих на безопасность воздушного движения, и может вызвать появление конкретной ситуации во время полета [3, с. 296]. Конкретная ситуация - результат действия опасных факторов и отражает значительное влияние на безопасность полетов. После анализа опасных факторов может быть произведена оценка вероятности их появления. Анализ проводится по группам опасных факторов в зависимости от уровня их влияния [2, с 144].

Оценка факторов риска определяет условия для полета, который, в свою очередь, требует классификации ситуации полета. Оценивается влияние каждого опасного фактора.

В таблице 2 приводится ограничения безопасности полета в соответствии с классом ситуации и типом БПЛА [1, с. 46].

В условиях нормальных условий полета чрезвычайно незначительные отклонения от требований летного задания производительность присутствует. Они не влияют на успех производительность и находятся в допустимых пределах погрешности измерительного оборудования. Летное задание выполняется в соответствии с требованиями безопасности и находится под непрерывным контролем.

В ситуации в сложных условиях полета желательно определить мизерные отклонения от требования летного задания. Отклонение параметров от плановых значений позволяет системе вернуться к летному заданию с учетом летно-технического ограничения. Непринятие решений о системе управление может привести к ухудшению полетной обстановки.

В сложной ситуации необходимо указать незначительные отклонения от требований летного задания. Отклонение параметров от плановых значений значительно усложняет процесс возврата в рейс задача. Необходимо решение по управлению системой для улучшение летной обстановки.
Чрезвычайная ситуация (ЧС) характеризуется существенным отклонением от требований летного задания. Значительные отклонения параметров от запланированных значений крайне усложняют процесс возврата к полетному заданию. Ситуация характеризуется значительным снижением уровня безопасности. Неконтролируемость ситуация может привести к катастрофе, поэтому есть необходимость в принятие решений по управлению системой.

Катастрофическая ситуация (KC) характеризуется невыполнением летного задания, связанного с критическим отклонением параметров от плановых значений. Катастрофические отклонения делают невозможным возврат к летному заданию. Необходимо учитывать летно-технические характеристики БПЛА, а также наличие незапланированных препятствий, приводящих к потере системы в целом.

\section{К^ассы полетной ситуации}

Определение класса существующей полетной ситуации является важный элемент миссии, особенно в случае с помощью датчиков БПЛА восстановлены данные [4, с 326]. Для метрики формулировка классов летных ситуаций воспользуемся критерием, учитывающим уровень отклонения БПЛА от требований летного задания. Для этого полетное задание должно содержать набор запланированных значений. Параметры задаются перед полетом с учетом всех его сложностей. В дальнейшем точное соблюдение запланированного параметров полета будут соответствовать нормальным условиям полета.

Технически установка значений параметров планового полета в многопараметрическом подходе является сложной задачей. Ее решают группы экспертов на основе накопленного опыта и с использованием имитационных моделей.

Еще одним важным элементом многовариантной классификаци - это установление метрики полета. Классы ситуаций, соответствуют определенному отклонению параметров от плановых значений до определенного уровня. Следует отметить, что уровни отклоне- 
ний различны для разных классов ситуаций и не могут быть рассчитаны линейно. Предлагается ввести значения плановых параметров, соответствующих определенному классу ситуации.

Этот параметр характеризует отклонение от планового значения в определенном метрическом пространстве и отражает определенное состояние БПЛА.

В случае многопараметрической классификации полета ситуаций предлагается оценить значение $Z$ для каждого класса полетной обстановки и по каждому из параметров.

Впоследствии метрика Z будет использоваться для вычисления апостериорной вероятности классов ситуаций.

В соответствии с вероятностью возникновения класс полетной ситуации, указанный в таблице, сформируем границы классов Z. Однако значение катастрофической ситуации должен настраивать пользователь на основании суждений о неудачном выполнении летного задания.

Задача порога ZCS состоит в определении границы отклонения БПЛА от заданной траектории, которая определяется координатами. Граница значения других параметров системы определяется ее техническими характеристиками и может быть рассчитаны с помощью математической модели БПЛА или с использованием экспертных оценок на определенный момент времени.

\section{Зак^ючение}

В статье проведен анализ различных видов беспилотных летательных аппаратов. Определены классы безопасного полета БПЛА в соответствии с типом БПЛА. Границы безопасности полетов представлены в соответствии с классом полетной обстановки и типом БПЛА. Это позволит адаптировать полетное задание для выполнения миссии БПЛА в соответствии с задачами и повысит ситуационную осведомленность оператора БПЛА.

\section{ЛИТЕРАТУРА}

1. Federal Aviation Administration AC23.1309-1E. System safety analysis and assessment for part 23 airlines. U.S. Department of Transportation, $2001,56 \mathrm{p}$.

2. Kharchenko V.P., Kuzmenko N.S., Ostroumov I.V. Identification of Unmanned Aerial Vehicle Flight Situation — 2017 IEEE4th International Conference Actual Problems of Unmanned Aerial Vehicles Developments (APUAVD)

3. Kharchenko V., Kuzmenko N., Kukush A., and Ostroumov I. Multiparametric data recovery for unmanned aerial vehicle navigation system - IEEE4th International Conference "Methods and Systems of Navigation and Motion Control" (MSNMC), 0ctober 18-20, 2016, pp. 295-299.

4. Mykhatsky 0. Yu., Kuzmenko N.S., Savchenko 0.V. Experimental UAV Flight Data Structuring, Transmission and Visualization by Narrowband Telemetry Transmission. - 2013 IEEE2nd International Conference "Actual Problems of Unmanned Air Vehicles Developments" Proceedings

5. Бондарев А.Н., Киричек Р.В. Обзор беспилотных летательных аппаратов общего пользования и регулирования воздушного движения БПЛА в разных странах // Информационные технологии и телекоммуникации. 2016. Т. 4. № 4.

6. Григорьев В.В., Бушуев А.Б., Коровьяков А.Н., Литвинов Ю.В. Анализ влияния ветровых возмущений на систему стабилизации курса летательных аппаратов* // Изв. вузов приборостроение.- 2013. Т. 56, № 4, С. 75-80

7. Замятин П.А. Вопросы эксплуатации беспилотных авиационных систем // Славянский форум, № 1 (31), 2021, с. 297-304

8. Замятин П.А. Классификационные признаки беспилотных летательных аппаратов аэродромного базирования // Chronos. - 2020. — № 4 (43). - C. 76-84.

9. Замятин П.А. Системы управления беспилотными летательными аппаратами // Инновационная наука. — 2020. — № 4.— C. 37-42.

10. Рэндал У. Биард, Тимоти У. Мак Лэйн Малые беспилотные летательные аппараты: теория и практика — Москва: ТЕХНОСФЕРА, 2015. — 312 с.

11. Шайтура С.В. Разработка технологии мониторинга района с использованием беспилотных летательных аппаратов // Славянский форум. - 2019.№ 2 (24). - С. 87-94.

12. Шайтура С.В., Барбасов В.К., Васкина М.Ю. Использование беспилотных систем в сельском хозяйстве - В сборнике: Методы и программные средства информационного сервиса в информационных и пространственных полях. Сборник научных трудов. Бургас, 2020. С. 118-124.

( Литвинов Юрий Георгиевич ( yurii-litvinov@mail.ru ), Керибаева Талшын Бакытжанкызы ( talshyn.keribayeva@gmail.com ).

Журнал «Современная наука: актуальные проблемы теории и практики» 